\title{
Preliminary Values of Diagnostic Reference Level for Selected X-Ray Examinations in Indonesia
}

\author{
E. Hiswara ${ }^{\star}$, H. Prasetio, D. Kartikasari, N. Nuraeni and K.Y.P. Sandy \\ Center for Radiation Safety Technology and Metrology, National Nuclear Energy Agency \\ Jl. Lebak Bulus Raya No. 49, Jakarta 12070, Indonesia
}

\section{ARTICLE INFO}

\section{Article history:}

Received 16 November 2015

Received in revised form 27 April 2016

Accepted 9 May 2016

\section{Keywords:}

Diagnostic radiology

Diagnostic reference levels

Adult patient doses

Entrance surface doses

Children patient doses

\begin{abstract}
A B S T R A C T
The diagnostic reference levels form an efficient, concise, and powerful standard for optimizing the radiation protection of a patient. With an aim to contribute toward the establishment of the Indonesian National Diagnostic Reference Levels (NDRLs), a nationwide survey of the entrance surface doses received by adult patients during the most typical X-ray examinations has been performed. A number of 44 hospitals in 21 cities located in Java, Bali, Sumatera, Kalimantan, and Sulawesi islands were selected randomly to participate in this survey. Eight most common adult $\mathrm{X}$-ray examinations in 13 projections, as well as four children $\mathrm{X}$-ray examinations in six projections, were included in the list of procedures under consideration. Hospitals of different sizes and levels using different X-ray machines were represented in the survey. Standard thermoluminescence dosemeters were applied to measure entrance surface dose (ESD). A total of 1493 patients, consisting of 1208 adults and 285 children, were included in this study. The data were analyzed statistically and the minimum, median, mean, maximum, first quartile, and third quartile values of ESDs were reported. The ESDs calculated (third quartile) for adults varied from $0.18 \mathrm{mGy}$ (for extremities AP) to $5.84 \mathrm{mGy}$ (for lumbar spine LAT), and for children they varied from $0.16 \mathrm{mGy}$ (for chest AP/PA) to $1.46 \mathrm{mGy}$ (for skull AP/PA). Considering the geographic spread and size of Indonesia, those third quartile values calculated can only be regarded as preliminary DRL values for Indonesia. Compared with data from other countries, the calculated ESDs in this study are in general lower than the ESDs in those countries.
\end{abstract}

\section{INTRODUCTION}

In 1996, the International Commission on Radiological Protection (ICRP) in its Publication 73 introduced the term "diagnostic reference level" (DRL) to describe a concept of identification of abnormally high doses in diagnostic radiology. It is defined as "a form of investigation level, applied to an easily measured quantity, usually the absorbed dose in air, or in a tissue-equivalent material at the surface of a simple standard phantom or a representative patient" [1].

The ICRP also recommended that the values should be selected by professional medical bodies,

* Corresponding author.

E-mail address: e.hiswara@batan.go.id

DOI: http://dx.doi.org/10.17146/aij.2016.515 reviewed at intervals that represent a compromise between the necessary stability and the long-term changes in observed dose distributions, and be specific to a country or region [1].

According to Vassileva and Rehani [2], diagnostic reference levels are not dose limits. In contrast to occupational dose limits, diagnostic reference levels should not be applied to individual patients, because one patient's body mass and habits may require a higher dose than those of a standard one.

Walker and van der Putten [3] stated that the use of DRLs provides a simple method of comparison between X-ray units from various manufacturers across a variety of practices. Once DRLs were established, standard procedures under the as-low-as-reasonably-achievable (ALARA) 
principle were employed to continually ensure that patient doses were kept below this reference value.

Given the various procedures available in $\mathrm{X}$-ray examinations, studies to determine the patient entrance surface doses for this particular medical application of radiation have been carried out in many countries and regions, e.g., the UK [4], Greece [5], Iran [6], Italy [7], Ghana [8], Saudi Arabia [9], India [10], and Switzerland [11]. Under IAEA projects, patient doses were also measured in 12 countries in Asia, Africa, and Eastern Europe [12], as well as in Latin America [13]. With a few exceptions, the majority of the reported entrance surface values were similar.

The introduction of reference dose levels [4] has extended the use of the DRL concept from common X-ray examinations into interventional studies. The radiation exposure to patients during interventional procedures has been quantified to establish national diagnostic reference levels in Kenya [14], while the diagnostic reference levels for pediatric interventional cardiology has also been sought [15].

In Indonesia, an estimation of patient doses in mammographic examination has been carried out [16]. The patient mean glandular dose obtained from this study was $1.6 \mathrm{mGy}$. Moreover, another study estimated that thymus and thyroid doses received by patient undergoing thorax examination were around 0.005-0.094 mGy and 0.009-0.104 mGy, respectively [17].

The present study is an attempt to evaluate the doses to patients undergoing general diagnostic $\mathrm{X}$-ray examinations in several hospitals in Indonesia. The aim of the study was to calculate average patient doses and to contribute to the establishment of the national diagnostic reference levels for most typical adult and children X-ray examinations performed in Indonesia.

\section{EXPERIMENTAL METHODS}

The survey was carried out during the years of 2010-2014. A number of 44 hospitals in 21 cities located in Java, Bali, Sumatera, Kalimantan, and Sulawesi islands were selected randomly to participate in this survey, representing a reasonable geographic spread and the size of Indonesia.

A total of 1489 patients, consisting of 1208 adults and 281 children, were included in this study. Children are defined as those of $\leq 16$ years old, which is slightly different from that applied in the UK $(\leq 15$ years old) [4].

Eight typical adult X-ray examinations (13 projections) were chosen for this study: chest
(Anterior Posterior (AP)/Posterior Anterior (PA), lateral (LAT), abdomen (AP), cervical (AP, LAT, oblique), lumbar spine (AP/PA, LAT), skull (AP/PA, LAT), extremities (AP), shoulder (AP), and pelvis (AP). For child patients, only four typical examinations (eight projections) were chosen: chest (AP/PA, LAT), abdomen (AP), skull (AP/PA, LAT), and extremities (AP). For each patient and $\mathrm{X}$-ray unit, the following parameters were recorded: sex, age, weight, height, focus-to-skin distance, field size, $\mathrm{kVp}$, and $\mathrm{mAs}$.

Measurements of entrance surface dose (ESD) were made using three individually-packed chips of TLD-100 from Thermo Scientific Harshaw. The chips were placed in the center of the beam on the patient's skin during examination, and then read using a Thermo Scientific Harshaw 3500 Manual TLD reader.

All the TLDs used were calibrated in the Secondary Standard Dosimetry Laboratory (SSDL) Jakarta at the Indonesian National Nuclear Energy Agency (BATAN). The standard deviation of the TLD batch was of the order of $5 \%$, with the overall uncertainty being $\leq 20 \%$ at the $95 \%$ confidence level. To validate the results of its measurement, the standard dosemeter used in the SSDL Jakarta for TLD calibration is periodically calibrated in a Primary Standard Dosimetry Laboratory (PSDL) that is an affiliated member of the IAEA/WHO Network of Secondary Standards Dosimetry Laboratories.

The third quartiles of the whole data of ESD obtained were then use to calculate the DRLs. Considering the geographic spread and size of Indonesia, the DRLs calculated in this study can only be regarded as preliminary DRL values for Indonesia

\section{RESULTS AND DISCUSSION}

Table 1 shows the patient information and exposure parameters for eight routine adult X-ray examinations in Indonesia. It is shown that the mean patient weight is $57-60 \mathrm{~kg}$, which is important in reducing the variability of ESD.

Table 1 also shows that the mean patient age was 30-48 years, which is younger compared to the ones in the UK survey (ages 41-66 years) [4].

The distribution of individual entrance surface doses (ESDs) for eight routine adult X-ray examinations in Indonesia is given in Table 2. The table presents the minimum, first quartile, median, mean, third quartile, and maximum ESD values obtained for each X-ray examination. The X-ray machines that were sampled in this 
survey were first compliance-tested to ensure that the machines were in a good and reliable condition. Only those passing the test against the established reference values were used in this survey. The values of the third quartiles obtained were then taken to be the Indonesian DRLs.

The mean entrance surface dose values per X-ray examination measured in this study are presented in Table 3, together with the ESD values measured in several countries $[4,6,8,12]$.

As can be seen in Table 3, most of the mean ESDs calculated in this study are lower than that in such developed countries as the UK, New Zealand, and Taiwan. Comparison with the Iranian data, however, also showed that the ESDs calculated in this study are lower, while the Ghanaian data showed that the ESDs are about the same in both studies.

The compliance test conducted to all X-ray machines before being used was believed to contribute to the low values of ESD measured. One can note, however, that the DRLs of chest AP/PA, chest LAT, and skull LAT are slightly higher than those of the UK. This might be due to tube voltage settings in this study being lower than those used in the UK. The voltage settings of chest AP/PA, chest LAT, and skull LAT in this study were between 40-117 kV, 67-96 kV and 41-70 kV, respectively (Table 1), while in the UK they were in the 62-125 kV, 70-125 kV, and 63-74 kV ranges. Another possibility is that the tube voltage settings are not adjusted properly according to patient chest thickness [4].

Table 1. Patient information and exposure parameters for eight routine adult X-ray examinations in Indonesia

\begin{tabular}{llcccc}
\hline \multicolumn{1}{c}{ Examination } & Projection & $\begin{array}{c}\text { Patient age } \\
(\text { years })\end{array}$ & $\begin{array}{c}\text { Patient } \\
\text { weight }^{*}(\mathrm{~kg})\end{array}$ & $\begin{array}{c}\text { Tube potential } \\
(\mathrm{kV})\end{array}$ & mAs \\
\hline Chest & AP/PA & $40(17-98)$ & $58(40-90)$ & $40-117$ & $9-80$ \\
Abdomen & LAT & $39(19-70)$ & $57(41-76)$ & $67-96$ & $14-32$ \\
Cervical spine & AP & $43(18-88)$ & $60(42-90)$ & $44-88$ & $12-80$ \\
& LAT & $45(20-70)$ & $59(40-83)$ & $46-77$ & $6-40$ \\
& Obliq & $45(20-71)$ & $59(40-84)$ & $46-77$ & $5-40$ \\
Lumbar spine & AP/PA & $48(34-71)$ & $58(58-60)$ & $46-77$ & $3-40$ \\
& LAT & $47(19-79)$ & $59(35-86)$ & $45-85$ & $0.9-64$ \\
Skull & AP/PA & $46(18-75)$ & $58(40-86)$ & $45-98$ & $0.6-50$ \\
& LAT & $45(18-73)$ & $60(40-90)$ & $41-85$ & $4.95-80$ \\
Extrimities & AP & $41(17-85)$ & $58(40-95)$ & $41-70$ & $10-90$ \\
Shoulder & AP/PA & $45(24-67)$ & $57(42-72)$ & $40-75$ & $3-50$ \\
Pelvis & AP/PA & $47(21-94)$ & $58(47-71)$ & $59-81$ & $2-13$ \\
\hline
\end{tabular}

${ }^{*}$ Mean values and range (in parentheses).

Table 2. Distribution of individual entrance surface dose (ESD) for eight routine adult X-ray examinations in Indonesia

\begin{tabular}{llccccccc}
\hline \multirow{2}{*}{ Examination } & Projection & Number & \multicolumn{6}{c}{ Entrance surface dose (mGy) } \\
\cline { 4 - 9 } & & & Min & $\begin{array}{c}\text { First } \\
\text { quartile }\end{array}$ & Median & Mean & Third & Max \\
quartile & \\
\hline Chest & AP/PA & 389 & 0.01 & 0.11 & 0,18 & 0.32 & 0.33 & 5.13 \\
& LAT & 30 & 0.05 & 0.37 & 0.73 & 0.95 & 1.18 & 4.09 \\
Abdomen & AP & 126 & 0.13 & 0.94 & 1.57 & 2.00 & 2.60 & 8.34 \\
& AP & 35 & 0.10 & 0.21 & 0.40 & 0.80 & 0.89 & 4.97 \\
& LAT & 28 & 0.02 & 0.24 & 0.38 & 0.66 & 0.92 & 2.05 \\
Lumbar spine & Obliq & 21 & 0.16 & 0.25 & 0.58 & 1.29 & 2.08 & 4.04 \\
& AP/PA & 81 & 0.08 & 1.35 & 1.99 & 2.45 & 3.41 & 8.01 \\
Skull & LAT & 72 & 0.11 & 2.49 & 4.29 & 4.67 & 5.84 & 25.72 \\
& AP/PA & 47 & 0.05 & 0.71 & 0.99 & 1.38 & 1.58 & 4.61 \\
Extrimities & LAT & 27 & 0.13 & 0.50 & 0.77 & 1.08 & 1.38 & 3.32 \\
Shoulder & AP & 308 & 0.01 & 0.06 & 0.10 & 0.21 & 0.18 & 1.94 \\
Pelvis & AP & 13 & 0.01 & 0.05 & 0.13 & 0.14 & 0.20 & 0.43 \\
& AP & 31 & 0.35 & 0.62 & 1.35 & 1.52 & 1.98 & 3.87 \\
\hline
\end{tabular}


In comparison with the results for Iran, all minimum voltage settings in Iran were higher than those used in this study. The minimum settings in Iran were $70,75,85$, and $85 \mathrm{kV}$ for chest PA, chest LAT, skull AP/PA, and skull LAT examinations, while this study used $40,67,41$, and $41 \mathrm{kV}$, respectively, for those examinations. The higher voltage used in Iran is possibly due to Iranians tending to have thicker bodies than Indonesians, so a higher X-ray energy is required to penetrate the patient's body to produce the good image that is needed.

From the comparison with the results from Ghana, it was found that whenever the ESD in Ghana was higher, the voltage setting was generally also higher. For cervical spine AP, for example, the Ghanaian values for ESD and voltage setting were $1.05 \mathrm{mGy}$ and $60-80 \mathrm{kV}$, while those of this study were $1.02 \mathrm{mGy}$ and $46-77 \mathrm{kV}$. In contrast, when the ESD and voltage setting for chest LAT in Ghana were $0.43 \mathrm{mGy}$ and 65-90 kV, those from this study were $0.95 \mathrm{mGy}$ and $67-96 \mathrm{kV}$.
These comparison results with developed as well as upper-middle-income countries, which showed that the ESDs calculated from this study were mostly lower than the ESDs from those countries, support the statement that "the common assumption or opinion that radiation doses to patients in developing countries are always higher than those in developed countries is not correct" [12].

Table 4 shows the patient information and exposure parameters for four routine children $\mathrm{X}$-ray examinations in Indonesia. The mean patient weight is limited to $23-42 \mathrm{~kg}$ to obtain a good estimation of the typical dose delivered to an average Indonesian child patient.

The distribution of individual entrance surface dose (ESD) for four routine children X-ray examinations in Indonesia is given in Table 5. As with Table 4 for the adult patients, Table 5 presents the minimum, first quartile, median, mean, third quartile, and maximum ESD values for each X-ray examination obtained. The third quartile values are then taken as the proposed national DRLs for children.

Table 3. Comparison of the mean entrance surface doses (in mGy) calculated in this study with those of other selected countries

\begin{tabular}{|c|c|c|c|c|c|c|c|}
\hline Examination & Projection & UK [4] & Iran [6] & Ghana [8] & This study & Taiwan [12] & $\begin{array}{c}\text { New Zealand } \\
{[12]}\end{array}$ \\
\hline \multirow[t]{2}{*}{ Chest } & $\mathrm{AP} / \mathrm{PA}$ & $0.2 / 0.15$ & 0.74 & 0.27 & 0.32 & 0.52 & 0.22 \\
\hline & LAT & 0.5 & 2.21 & 0.43 & 0.95 & - & - \\
\hline Abdomen & $\mathrm{AP}$ & 4 & - & - & 2.00 & 4.77 & 20.4 \\
\hline \multirow[t]{3}{*}{ Cervical spine } & AP & - & - & 1.05 & 0.80 & - & - \\
\hline & LAT & - & - & 0.45 & 0.66 & - & - \\
\hline & Obliq & - & - & - & 1.29 & - & - \\
\hline \multirow[t]{2}{*}{ Lumbar spine } & $\mathrm{AP} / \mathrm{PA}$ & 5.7 & - & 3.25 & 2.45 & 5.91 & 22.8 \\
\hline & LAT & 10 & - & - & 4.67 & 18.9 & 35.5 \\
\hline \multirow[t]{2}{*}{ Skull } & $\mathrm{AP} / \mathrm{PA}$ & 1.8 & 6.84 & - & 1.38 & 2.6 & 3.0 \\
\hline & LAT & 1.1 & 7.89 & - & 1.08 & - & - \\
\hline Extremities & $\mathrm{AP}$ & - & - & - & 0.21 & - & - \\
\hline Shoulder & AP & 0.5 & - & - & 0.14 & - & - \\
\hline Pelvis & AP & 4 & - & 1.31 & 1.52 & 5.13 & 21.4 \\
\hline
\end{tabular}

Note: dash (-) indicates no data available.

Table 4. Patient information and exposure parameters for four routine children X-ray examinations in Indonesia

\begin{tabular}{llcccc}
\hline Examination & Projection & $\begin{array}{c}\text { Patient age } \\
(\text { years })\end{array}$ & $\begin{array}{c}\text { Patient weight } \\
(\mathrm{kg})\end{array}$ & $\begin{array}{c}\text { Tube potential } \\
(\mathrm{kV})\end{array}$ & mAs \\
\hline Chest & AP/PA & $10-16$ & $28-40$ & $40-96$ & $12-25$ \\
& LAT & $10-15$ & $20-35$ & $44-68$ & $3.5-6.3$ \\
Abdomen & AP/PA & $7-12$ & $25-40$ & $40-63$ & $15-24$ \\
Skull & AP/PA & $9-16$ & $28-42$ & $44-72$ & $15-50$ \\
& LAT & $9-15$ & $25-42$ & $52-72$ & $25-32$ \\
Extrimities & AP & $11-16$ & $29-40$ & $40-68$ & $24-50$ \\
\hline
\end{tabular}


Table 5. Distribution of individual entrance surface dose (ESD) for four routine children X-ray examinations in Indonesia

\begin{tabular}{llccccccc}
\hline \multirow{2}{*}{ Examination } & Projection & Number & Min & $\begin{array}{c}\text { First } \\
\text { quartile }\end{array}$ & Median & Mean & $\begin{array}{c}\text { Third } \\
\text { quartile }\end{array}$ & Max \\
\cline { 5 - 9 } & & & & & & & \\
\hline
\end{tabular}

Table 6 shows the comparison between DRLs calculated for children in this study (third quartile values) with the DRLs for 5- to 9-year olds suggested in India [18]. This comparison shows that in general both sets of DRL values are about the same, albeit the range of patient ages in this study are slightly higher than that in India which is 5- to 9-years old [18].

For the UK data, the UK sets reference levels for children representing ages of $0,1,5$, 10 , and 15 years [4]. However, the reference levels are given only for micturating cystourethrography (MCU), barium meal and barium swallow, and are given in the unit of dose area product (DAP, Gy.cm²). As such, the calculated DRLs resulted from this study that were given in ESD (mGy) cannot be compared to those applied in the UK.

Table 6. Comparison of DRLs for child patients in this study with Indian values (in $\mathrm{mGy}$ )

\begin{tabular}{llcc}
\hline Examination & Projection & India [18] & This study \\
\hline Chest & AP/PA & 0.2 & 0.16 \\
\multirow{2}{*}{ Abdomen } & LAT & 0.3 & 0.60 \\
Lumbar spine & AP & 0.5 & 0.56 \\
& LAT & 0.7 & - \\
Skull & AP/PA & 1.3 & - \\
& LAT & 0.6 & 1.46 \\
Extrimities & AP & - & 0.84 \\
\hline
\end{tabular}

As a summary, the values of diagnostic reference levels for selected X-ray examinations in Indonesia, as calculated from the third quartile values, are given in Table 7. However, since Indonesia is a large country, the sample size from this study is quite limited; thus, that the calculated DRLs can only be regarded as preliminary DRL values for Indonesia

Tabel 7. Preliminary values of DRL for Indonesia (in mGy)

\begin{tabular}{llcc}
\hline Examination & Projection & Adult & Children \\
\hline Chest & AP/PA & 0.33 & 0.16 \\
& LAT & 1.18 & 0.60 \\
Abdomen & AP & 2.60 & 0.56 \\
Cervical & AP & 0.89 & - \\
spine & LAT & 0.92 & - \\
& Obliq & 2.08 & - \\
Lumbar & AP/PA & 3.41 & - \\
spine & LAT & 5.84 & - \\
Skull & AP/PA & 1.58 & 1.46 \\
& LAT & 1.38 & 0.84 \\
Extremities & AP & 0.18 & 0.24 \\
Shoulder & AP & 0.20 & - \\
Pelvis & AP & 1.98 & - \\
\hline
\end{tabular}

\section{CONCLUSION}

This study presents the results of measurements of the doses absorbed by adult and child patients undergoing X-ray examinations in Indonesia, and calculated the diagnostic reference levels (DRLs) for most typical X-ray examinations performed. It has been seen that adult patient doses in Indonesia, which is often classified as a developing country, are in general lower than those in such developed or high-income countries as the UK, New Zealand, and Taiwan, as well as uppermiddle-income countries such as Iran, but are about the same with those of Ghana. The suggested DRL values for children, however, are about the same as those calculated for India. In order to calculate DRLs comprehensively for the whole country, the sample size should be increased, both in terms of number of patients and types of examinations. 


\section{ACKNOWLEDGMENT}

The authors acknowledge technical support from Mmes. Dyah D. Kusumawati, Helfi Yuliati, and Suyati, and Mr. Eka D. Nugraha, who have performed the measurements in the hospitals and in the laboratory. The cooperation of the hospitals that were sampled is most appreciated.

\section{REFERENCES}

1. Anonymous, Radiological Protection and Safety in Medicine, ICRP Publication 73, Ann. ICRP 26 (1996) 23.

2. J. Vassileva and M. Rehani, AJR 204 (2015) W1.

3. C. Walker and Wil van der Putten, Phys. Med, 28 (2012) 7.

4. D. Hart, M.C.Hillier and P.C. Shrimpton, Doses to patients from radiographic and fluoroscopic X-ray imaging procedures in the UK - 2010 review, HPA-CRCE-034, Oxfordshire: HPA, 2012.

5. S. Vogiatzi, P. Kipouros and M. Chobis, Radiat. Prot. Dosim. 147 (2011) 237.

6. D. Shahbazi-Gahrouei and M. BaradaranGhahfarokhi, Adv. Biomed. Res. 1 (2012) 11.

7. G. Compagnone, P. Angelini and S. Domenichelli, Radiol. Med. 117 (2012) 312.

8. K. Ofori, S.W. Gordon, E. Akrobortu et al.,
J. Radiat. Res. Appl. Sci. 7 (2014) 459.

9. M.K. Saeed, Australas. Phys. Eng. Sci. Med. 38 (2015) 299.

10. A. Saravanakumar, K. Vaideki, K.N. Govindarajan et al., J. Med. Phys. 39 (2014) 50.

11. E.T. Samara, A. Aroua, F.O. Bochud et al., Health Phys. 102 (2012) 263.

12. W.E. Muhogora, N.A. Ahmed, A. Almosabihi et al., AJR 190 (2008) 1453.

13. S. Blanco, P. Mora, N. Almonte et al., Radiat. Prot. Dosim. 156 (2013) 303.

14. G.K. Korir, J.S. Wambani, C.A. Yuko-Jowi, et al., Radiography 20 (2014) 148.

15. S. McFadden, C. Hughes, C.I. D'Helft et al., Radiography 19 (2013) 295.

16. N. Nuraeni, D. Milvita, I. Widora et al., Estimation of Mean Glandular Dose (MGD) using Technical Reports Series (TRS) 457 Protocol In Mammography Examination, Proc. National Seminar on Health, Safety and Environment VII (2011) 21. (in Indonesian).

17. H. Yuliati, H. Prasetio, Suyati et al., Organ Dose Estimation in Thymus and Thyroid of Patient Thorax Photo with Alculation, Proc. Scientific Meeting and Presentation on Functional of Nuclear Technology Development VII (2012) 157. (in Indonesian).

18. A.U. Sonawane, J.V.K. Sunil Kumar, M. Singh et al., Radiat. Prot. Dosim. 147 (2011) 423. 